\title{
Short communication: Influence of sampling interval on the accuracy of predicting bulk milk somatic cell count
}

\author{
J. J. Lievaart, ${ }^{\star 1,2}$ J. K. Reneau, † W. D. J. Kremer, ${ }^{\star}$ and H. W. Barkema $§$ \\ *University of Utrecht, Department of Farm Animal Health, Faculty of Veterinary Medicine, $3584 \mathrm{CL}$, Utrecht, the Netherlands \\ †Department of Animal Science, College of Food, Agricultural and Natural Resource Sciences, University of Minnesota, St. Paul 55108-6118 \\ $\ddagger$ Department of Production Animal Health, Faculty of Veterinary Medicine, University of Calgary, Calgary, AB, Canada T2N $2 Z 6$ \\ §Department of Reproduction, Obstetrics and Herd Health, Faculty of Veterinary Medicine, Ghent University, 9820, Merelbeke, Belgium
}

\begin{abstract}
Although bulk milk somatic cell count (BMSCC) is, in most instances, not a good proxy for actual average herd somatic cell count (SCC), BMSCC is the only SCC parameter available to monitor trends in udder health for a large number of farms worldwide. The frequency of sampling BMSCC varies considerably between countries, and it is unknown to what extent the sampling interval of BMSCC or variation in BMSCC data itself influences the accuracy. The aim of this study was to assess the effect of sampling interval and variation of the BMSCC data on the accuracy to predict BMSCC. Because BMSCC is measured at regular time intervals, an artificial neural network (ANN) was used to determine both the effect of sampling interval and variation of the BMSCC data. The intervals examined in this study ranged from 4 to $14 \mathrm{~d}$ and were compared with the baseline of a standard 2-d sampling interval. The BMSCC data were collected every other day for a 24mo period on 949 farms, and all series were created by exclusion of BMSCC data in between the original 2-d sampling interval series. The effect of variation of BMSCC was determined by comparing the error of the ANN model in 2 subsets of farms, those with the lowest $\mathrm{SD}(\mathrm{n}=239)$ and those with a high SD of BMSCC data $(\mathrm{n}=236)$. No significant differences were found in any of the sampling intervals between the 2 cohorts of low and high SD in BMSCC. Overall, compared with the 2-d sampling interval, on average the error of the ANN model was 32,600 cells/mL for all farms included, ranging from 15,000 cells $/ \mathrm{mL}$ (4-d interval) to 41,000 cells/ $\mathrm{mL}$ (14-d sampling interval). Therefore, the length of the sampling interval greatly influences the usefulness

\footnotetext{
Received June 27, 2010.

Accepted November 2, 2010.

${ }^{1}$ Current address: E H Graham Centre for Agricultural Innovation

${ }^{2}$ Corresponding author: jlievaart@csu.edu.au
} (an alliance between Charles Sturt University \& NSW Department of Primary Industries), Locked Bag 588, Wagga Wagga NSW 2678, Australia.
\end{abstract}

of BMSCC data to monitor trends in udder health at the herd level.

Key words: bulk milk somatic cell count, sampling frequency, variation, artificial neural network

\section{Short Communication}

The average of all individual SCC data is the most accurate parameter to summarize the subclinical mastitis situation in a dairy herd (Lievaart et al., 2007). However, a large proportion of dairy herds does not participate in DHI milk recording (Wiggans, 2009), and therefore bulk milk SCC (BMSCC) is in these herds the only available parameter to assess trends in actual average herd SCC and the prevalence of subclinical mastitis at the herd level (Jayarao et al., 2004). Compared with assessments from individual-level data, we have shown that BMSCC, when sampled at the same frequency, can lead to an underestimation of the average herd SCC of tens of thousands of cells $/ \mathrm{mL}$ (Lievaart et al., 2009).

The frequency of sampling BMSCC varies between countries and even between dairy processors within countries. Sampling frequency ranges from sampling every milk collection to one sample every $14 \mathrm{~d}$; thus, not every bulk tank is monitored for BMSCC (Goodridge et al., 2004). In general, the accuracy of describing a time-series variable such as BMSCC depends on the sampling interval and variation of the data (Anderson et al., 1989). To date, it is unknown how the sampling interval influences the accuracy of BMSCC data, and whether this influence is likely to be different for farms with low versus high variability in BMSCC. The relatively high sampling frequency of BMSCC data in some countries provides an opportunity to address these questions. The aims of this study were to determine the optimal sampling interval for BMSCC data, including the influence of the variation of BMSCC on these sampling intervals.

The original data set included BMSCC data that were collected daily or every other day for at least 2 mo of the 24-mo period (January 2003 to December 


\section{Input Layer \\ Hidden Layer \\ Output Layer}

Input LN BMSCC data

Described LN BMSCC data point

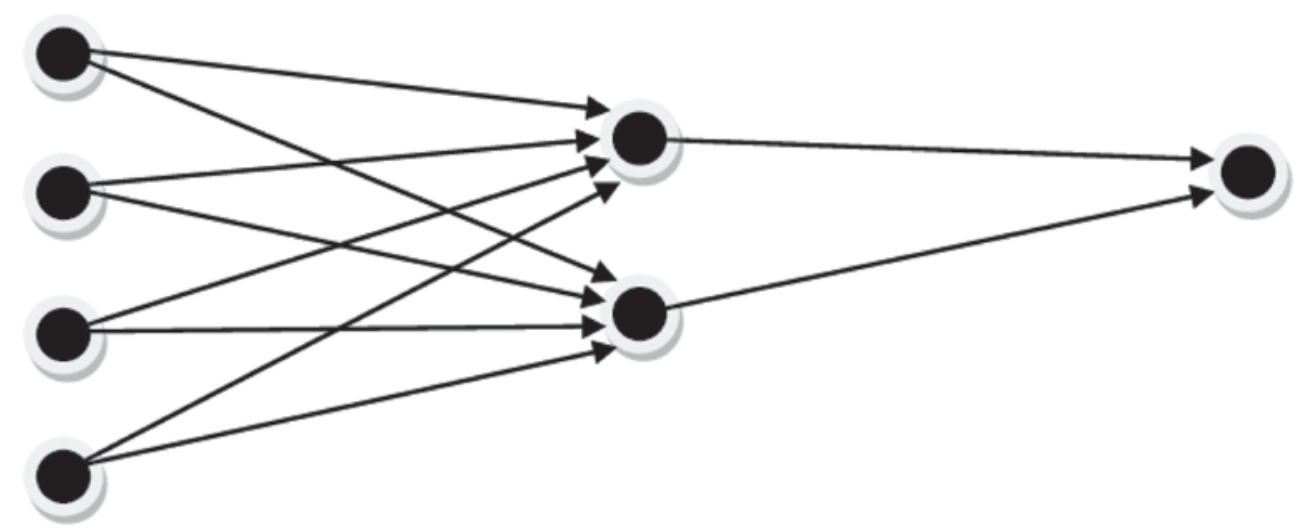
SCC.

Figure 1. Schematic overview of an artificial neural network with input, hidden, and output layers. LN BMSCC = natural log bulk milk

2004) from 1,501 (6.4\% of the total population) dairy farms in the Upper Midwest (North and South Dakota, Wisconsin, and Minnesota; Lukas et al., 2008a,b). No additional data on parity, herd size, or average DIM were available for any of the farms. For the current study, farms in the original data set were included only if they had a complete BMSCC data set for all months of the 24-mo period and a sampling interval of BMSCC of $2 \mathrm{~d}$ (baseline data set). In total, 949 of the 1,501 herds fitted these criteria. Six additional data sets with sampling intervals of $4,6,8,12$, and $14 \mathrm{~d}$, respectively, were created through re-sampling of the baseline data by exclusion of BMSCC data in the baseline at appropriate times depending on the interval.

To test the influence of variation on the accuracy of describing BMSCC data series, we divided the selected 949 farms with a complete data set into low- and high BMSCC variation cohorts of BMSCC data. To create these 2 cohorts, all BMSCC were transformed on a natural logarithmic scale to gain a normal distribution of the BMSCC data. The standard deviation (SD) of BMSCC was determined over this 2-yr period and the farms with the low or high variation of BMSCC data were defined as the farms belonging to the lowest and highest $25 \% \mathrm{SD}$ of BMSCC, respectively. All data were back-transformed from the natural logarithmic scale for presentation purposes.

To describe the BMSCC data series in this study, the time-series analysis option of the Alyuda NeuroIntelligence 2.2 (2005; Alyuda Research, Los Altos, CA) software program was used. Artificial neural networks (ANN) are frequently used in human and veterinary medicine and agriculture to predict the outcome of a disease process (Bartosch-Härlid et al., 2008), as diagnostic support (Heald et al., 2000), or for simulation of nonlinear data series (Njubi et al., 2010). These ANN can be seen as an organized network of artificial neurons or data points that process the data with constant feedback to constantly optimize the end result (Gurney, 1997; Hassan, 2007). For each BMSCC data set with sampling intervals ranging from 4 to $14 \mathrm{~d}$, the $3 \mathrm{mo}$ of data preceding the predicted BMSCC value were used to train, validate, and test the ANN model. For all series we used an input layer with all data points of the preceding 3 mo (which now becomes the number of neurons), one hidden layer with half the number of neurons, and one output neuron (the described data point; see example neural network in Figure 1).

The program used $60 \%$ of the data points to train the model, $20 \%$ to validate the model and $20 \%$ to test the chosen model in how well it described the baseline BMSCC series. For this study the algorithm QuickProp (NeuroIntelligence 2.2, Alyuda Research) was used with 5,000 iterations per model to find the best combination of weights for each neuron (or, in this case, BMSCC data point) to include for the next layer of neurons. We used the ANN model to predict a 2-d time-series for all re-sampled data sets with the sampling intervals ranging from 4 to $14 \mathrm{~d}$ within both the low and high SD cohorts of BMSCC data. Subsequently, to assess different sampling intervals, we calculated the error between this prediction and the actual 2-d baseline values. A general linear model (GLM) was used to examine whether sampling interval or SD cohort had an effect on the error and if there was an interaction between those 2 variables. If the variable "sampling interval" 


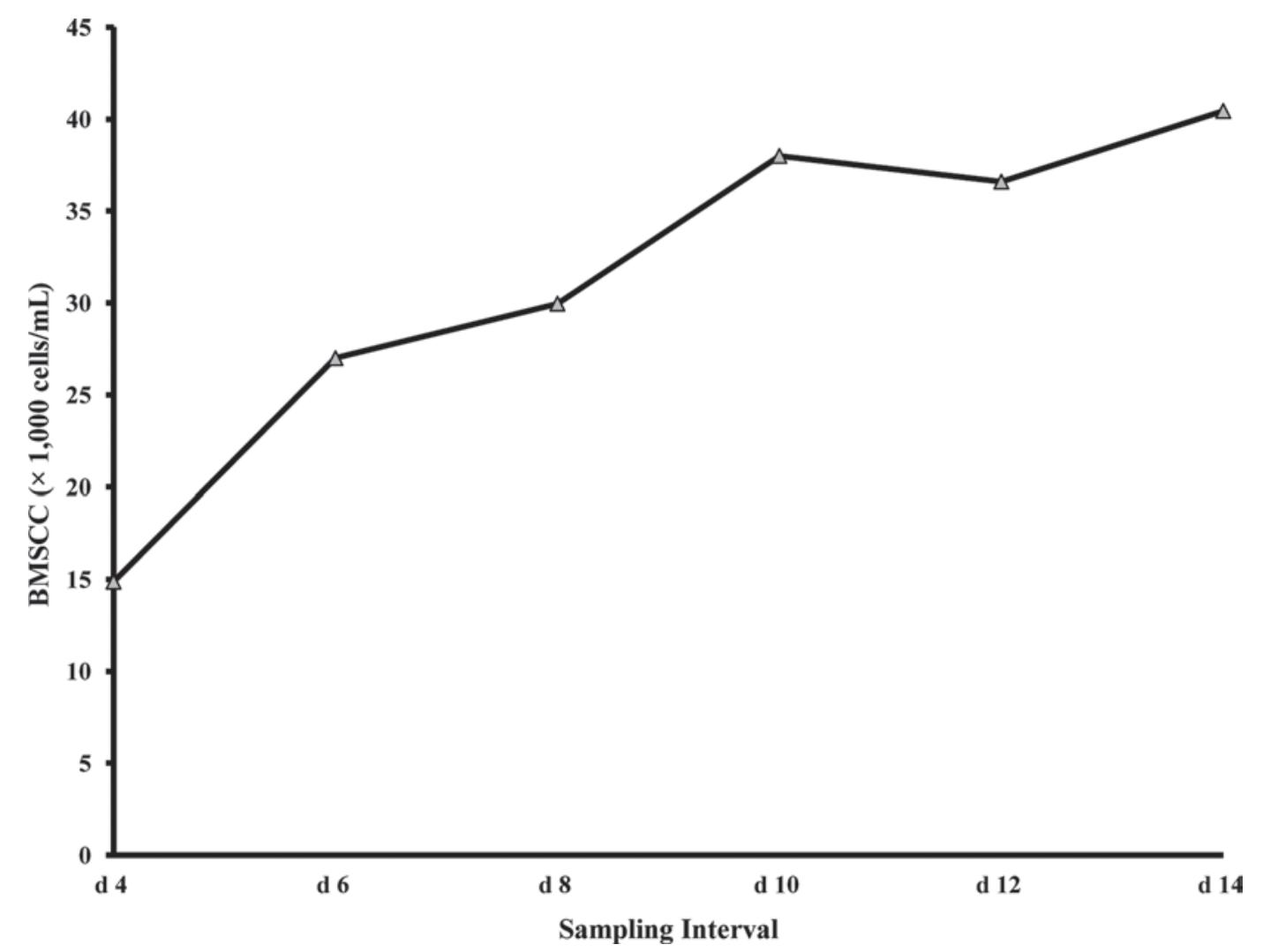

Figure 2. The average error of bulk milk SCC series (BMSCC; $\times 1,000$ cells $/ \mathrm{mL}$ ) for 6 sampling intervals (d) using artificial neural network (ANN) models.

was significant $(P<0.05)$ in the GLM, a further investigation using an ANOVA with a post-hoc Bonferroni test was done to examine which sampling intervals were different from the other intervals.

The 949 farms had a geometric average BMSCC of 267,000 cells $/ \mathrm{mL}$ (range 111,000-665,000 cells/mL) with an average SD of 108,000 cells $/ \mathrm{mL}$. The cohort of low SD farms included 239 farms that had an average BMSCC of 186,000 (range 111,000 to 424,000 cells/mL) and an SD of 75,000 cells $/ \mathrm{mL}$. The cohort of high SD farms included 241 farms with an average BMSCC of 478,000 (range 151,000 to 665,000 cells $/ \mathrm{mL}$ ) and an $\mathrm{SD}$ of 149,000 cells $/ \mathrm{mL}$.

Sampling interval was the only significant variable $(P<0.01)$ in the GLM to determine the influence of sampling interval or cohort (high or low SD) of BMSCC. No significant interaction was found between the variables of cohort (high and low SD) and sampling interval. The average error of the ANN model in describing BMSCC series for all sampling intervals was 32,600 cells $/ \mathrm{mL}$. The sampling interval of $4 \mathrm{~d}$ had the lowest error, 15,300 cells $/ \mathrm{mL}$, and was significantly lower $(P$ $=0.02)$ compared with all other intervals. The errors from the other sampling intervals ranged from 27,200
cells/mL for the 6 -d interval to 40,400 cells/mL for the 14-d sampling interval (Figure 2).

Although BMSCC is an important udder health parameter, which is in most cases readily available with a relatively short sampling interval, it is not always the most reliable tool to monitor udder health on dairy farms (Lievaart et al., 2007, 2009). The current study shows that an additional deviation of between 15,000 and 40,000 cells/mL could be caused by the choice of sampling interval. To monitor udder health at the herd level using BMSCC data would therefore only be suitable to identify rough trends, and it seems of limited use to underpin decisions in short-term udder health management.

Given these limitations, a large number of farmers still depend on the BMSCC as the only indicator of udder health, or more specifically to monitor subclinical infections in their herd. The proportion of dairy herds that participates in a DHI program ranges from $21 \%$ in Poland to $94 \%$ in Denmark (International Committee for Animal Recording, 2008). In January 2009, $48 \%$ of the US dairy cow population was not enrolled in a DHI program, whereas SCC was determined on $94 \%$ of the enrolled cows (Wiggans, 2009). However, when farmers 
do have access to individual SCC recordings, these are sometimes of limited use for short-term monitoring of udder health because of the relatively long sampling interval of DHI programs ranging from 3 to $6 \mathrm{wk}$.

In this study we did not quantify the absolute error of the BMSCC as a proxy to measure the actual herd SCC. The latter is unknown and we should therefore make do with a relative assessment. For this we assumed that the accuracy of BMSCC is constant throughout the year for a given farm and sampling strategy. We further assume that the most frequent sampling gives the most accurate description of the actual situation, even though we do not quantify how accurate that is. Our relative measure refers only to the additional uncertainty introduced by less frequent sampling. In addition, because the sampling intervals in this study were artificially created by deleting data points within a single baseline time-series, dependency exists in our procedure. One has to keep in mind that farms used in this data set were monitored every other day; therefore, farmers could be aware of an increase in BMSCC within $48 \mathrm{~h}$ and react to this information. Farms with an actual sampling interval of $14 \mathrm{~d}$ would automatically have a delay to a response in BMSCC, which could result in increased variation in BMSCC data, which we have not accounted for. Therefore, our quantitative results should be seen as indicative of, not as absolute predictions of, error. The results should be tested on different data sets from different countries with different sampling intervals. Moreover, no influence was found of variability (measured by SD) of BMSCC on the accuracy of BMSCC for different sampling intervals. The reason may lie in the ANN technique used and the ability of this technique to deal with data demonstrating an irregular pattern (Gurney, 1997).

In the current study we included only the variation of BMSCC to examine its effect on sampling interval. Other factors could contribute to further inaccuracy. Days in milk and average parity are both associated with an increasing prevalence of subclinical mastitis and increased SCC (Laevens et al., 1997; Breen et al., 2009). Therefore, in future studies, other variables that could influence variation in BMSCC, such as herd size or average parity, should be examined more closely.

\section{REFERENCES}

Anderson, S. M., I. L. Mao, and J. L. Gill. 1989. Effect of frequency and spacing of sampling on accuracy and precision of estimating total lactation milk yield and characteristics of the lactation curve. J. Dairy Sci. 72:2387-2394.

Bartosch-Härlid, A., B. Andersson, U. Aho, J. Nilsson, and R. Andersson. 2008. Artificial neural networks in pancreatic disease. Br. J. Surg. 95:817-826.

Breen, J. E., M. J. Green, and A. J. Bradley. 2009. Quarter and cow risk factors associated with the occurrence of clinical mastitis in dairy cows in the United Kingdom. J. Dairy Sci. 92:2551-2561.

Goodridge, L., A. R. Hill, and R. W. Lencki. 2004. A review of international standards and the scientific literature on farm milk bulktank sampling protocols. J. Dairy Sci. 87:3099-3104.

Gurney, K. 1997. An Introduction to Neural Networks. UCL Press, London, UK.

Hassan, K. J. 2007. Application of artificial neural networks for understanding and diagnosing the state of mastitis in dairy cattle. MS Thesis. Lincoln Univ., Canterbury, New Zealand.

Heald, C. W., T. Kim, W. M. Sischo, J. B. Cooper, and D. R. Wolfgang. 2000. A computerized mastitis decision aid using farm-based records: An artificial neural network approach. J. Dairy Sci. $83: 711-720$

International Committee for Animal Recording. 2008. Results for the years 2008-2009: Yearly enquiry on the situation of cow milk recording in member countries. Accessed June 2010. http://www. icar.org/.

Jayarao, B. M., S. R. Pillai, A. A. Sawant, D. R. Wolfgang, and N. V. Hegde. 2004. Guidelines for monitoring bulk tank milk somatic cell and bacterial counts. J. Dairy Sci. 87:3561-3573.

Laevens, H., H. Deluyker, Y. H. Schukken, R. Vandermeersch, E. De Mulenaere, and A. De Kruif. 1997. Influence of parity and stage of lactation on the somatic cell count in bacteriologically negative dairy cows. J. Dairy Sci. 80:3219-3226.

Lievaart, J. J., H. W. Barkema, H. Hogeveen, and W. D. J. Kremer. 2009. Reliability of the bulk milk somatic cell count as an indication of average herd somatic cell count. J. Dairy Res. 76:490496

Lievaart, J. J., W. D. J. Kremer, and H. W. Barkema. 2007. Comparison of bulk milk, yield-corrected, and average somatic cell counts as parameters to summarize the subclinical mastitis situation in a dairy herd. J. Dairy Sci. 90:4145-4148.

Lukas, J. M., J. K. Reneau, and M. L. Kinsel. 2008a. Predicting somatic cell count standard violations based on herd's bulk tank somatic cell count. Part I: Analyzing variation. J. Dairy Sci. 91:427-432.

Lukas, J. M., J. K. Reneau, C. Munoz-Zanzi, and M. L. Kinsel. 2008b. Predicting somatic cell count standard violations based on herd's bulk tank somatic cell count. Part II: Consistency index. J. Dairy Sci. 91:433-441.

Njubi, D. M., J. W. Wakhungu, and M. S. Badamana. 2010. Use of test-day records to predict first lactation 305-day milk yield using artificial neural network in Kenyan Holstein-Friesian dairy cows. Trop. Anim. Health Prod. 42:639-644.

Wiggans, G. R. 2009. USDA Summary of DHI Participation (DHI Report K-1). Accessed June 2010. http://aipl.arsusda.gov/publish/ dhi/current/partall.html. 